\title{
Living with HIV/AIDS among men having sex with men (MSM) in the Philippines: internet ethnography of HIV life stages
}

Cyruz P Tuppal', Marina Magnolia G Ninobla², Mark Donald C. Reñosa ${ }^{3}$, Mara Gerbabe D Ruiz ${ }^{4}$, Richard C Loresco Shanine Mae P Tuppal ${ }^{6}$, Iril I Panes ${ }^{7}$

1 School of Health Science Professions, St. Dominic, College of Asia, Bacoor, Cavite, Philippines; Graduate School, St. Paul University Philippines System, Tuguegarao City, Cagayan Valley, Philippines, ${ }^{2}$ College of Nursing, Muscat Branch, Ministry of Health, Muscat, Sultanate of Oman, 3 Department of Epidemiology and Biostatistics, Research Institute for Tropical Medicine, Department of Health, Muntinlupa City, Philippines, 4 College of Nursing, Sur Branch, Ministry of Health, Muscat, Sultanate of Oman, 5 Infection Prevention and Control Department, Higher Institute of Health Specialties, Ministry of Health, Muscat, Sultanate of Oman, ${ }^{6}$ Nursing Service Department, National Kidney Transplant Institute, Diliman, Quezon City, Philippines, ${ }^{7}$ College of Nursing, Sultan Kudarat State University, Tacurong City, Sultan Kudarat, Philippines

Keywords: msm, hiv/aids, philippines, global health

https://doi.org/10.29392/joghr.3.e2019090

\section{Journal of Global Health Reports}

Vol. 3, 2019

\section{Background}

There is lesser attention given to Internet research using personal online blogs that can offer a valid source of information from an emic naturalistic perspective to define the meaning and essence in the life stages among men having sex with men living with HIV/ AIDS in the Philippines. This study aims to capture, illuminate, and define the meaning and essence in the life stages among men having sex with men living with HIV/AIDS in the Philippines.

\section{Methods}

This study utilized Internet ethnography design. A total of 16 personal online blogs were purposively sampled from Blogger and Word press, which were retracted, appraised, and saved in the word document. Through line-by-line reading and textual immersion, the meaning and essence in the life stages among men who have sex with men (MSM) living with HIV/AIDS in the Philippines were captured, illuminated, and defined.

\section{Results}

The HIV life stages among MSM living with HIV/AIDS in the Philippines include Stage I Pre-HIV Exposure, Stage II HIV Exposure, Stage III Presumptive Symptomatology, Stage IV Diagnosis, and Confirmatory, and Stage V Post-HIV Diagnosis and Treatment.

Accompanying each stage are the psycho-emotive components such as awareness-invincibility, familiarity-vulnerability, denial-disbelief, dispiritedness-depression, and fear-discriminant disclosure that can be addressed by the relational agency's distinct but interrelated values system. ' $I$ am still me' is the overall representation of the meaning and essence in the life stages among MSM living with HIV/ AIDS in the Philippines.

\section{Conclusion}

The fight against the disease does not offer a one-size-fits-all strategy but should be holistic, comprehensive, integrative, humanistic, and compassionate. From then, we could say-we are arriving at "the end of stigma." "We are ONE" and "We are in communion in caring with PLWHA" must be revitalized into national and global agenda.

In the Philippines, numerous studies indicate that there is a linear growth of cases among high-risk groups including young adults, commercial sex workers, injecting drug users, overseas Filipino workers, men who have sex with men (MSM) and the sexual partners of people in these groups. ${ }^{1}$ The country has increased its incidence among MSM from 2003-2010, reaching 114\% among bisexual men and 214\% among homosexual men. ${ }^{2}$ Among groups of MSM including a range of business process outsourcing employees (BPOEs), healthcare workers, seafarers, students, employed, and unemployed ( $N=406), 48(11.8 \%)$ were HIV positive in a rapid test due to non-use of condom preference for receptive anal sex, and sex while under the influence of excessive alcohol. ${ }^{3}$ Young, sexually active MSMs were also conceived as transmitters of HIV based on the anecdotal data although the findings indicate high knowledge of HIV but the majority had sexual risk-taking behaviors in terms of non-use of condoms (43.7\%) compared to those who used (45.2\%) and consistent use (28.6\%). ${ }^{4}$ Also, the new HIV cases acquired from men having sex with men (MSM) is considered as the primary driver of the epidemic in the Philippines from the period of 2007-2018 compared to cases of male-to-female or female-male sex between 1984-2016. ${ }^{5}$

People living with HIV/AIDS (PLWHA) mainly, MSM living with HIV/AIDS (MSMLWHA) have fought a good battle and still continuously fighting the disease. PLWHA show indication of infection with HIV $^{6}$ and many of them are ambivalent about revealing the truth about their status, have 
chosen to remain tongue-tied, hand-cuffed, and desolated from friends, family, or even society. The stigma has also been in existence even before HIV/AIDS became epidemic, and most if not all, PLWHA would have unique experiences to tell. 7,8

Stigma is interwoven with culture, time, and society that made it difficult to understand and define. ${ }^{9}$ Goffman (1986) introduced the concept of stigma in his book Stigma: Notes on the Management of Spoiled Identity as character traits, physical shame, and stigma of group identity. ${ }^{9}$ Stigma makes the individual an outcast, viewed as having an abnormal status, and does not meet social relevance or social acceptance. When stigma continues, it leads to isolation, depression, stress, and suicidal ideations. ${ }^{10,11}$ Moreover, the PLWHA would find it challenging to experience social connectedness, which eventually disrupts the relationship with others, and deprives health-seeking behaviors. ${ }^{10-14}$

The blogosphere has proliferated through social networking sites (SNNs) as a mode of communication to get in contact with new people, keep in touch with friends, and socialize. Blogs are commonly referred to as weblogs, online journals or diaries that offer life-story narration about a phenomenon of interest, specific subject or content, or even illness. As such, the bloggers have contributed to the widening scope of internet research from a longitudinal perspective on meaning-making, and knowing-meaning about the person's lived experiences. Many have resorted to the use of blogs primarily, PLWHA for self-disclosure, social connectedness, share their experiences, emotions, and feelings about the abrupt life transition. ${ }^{15}$ Although some studies have been conducted exploring the lived experiences of PLWHA, the evidence remains sparse within the culturespecific primarily in the Philippines. At this juncture, this Internet ethnography as a prelude to future exploration has examined the lived experiences to capture, illuminate, and define the meaning and essence in the life stages among MSM living with HIV/AIDS in the Philippines.

\section{METHODS}

Internet users are embodied users to express an embodied self. ${ }^{16}$ This means that people do not find the internet as an escape from everyday existence but to inform and enrich their understanding of either foreseen or unforeseen events in their lives. The web "can shape our experience of embodiment as the information and insights we find online help us to understand ourselves in new ways (p. 44)". ${ }^{16}$ This description further explains that the internet offers a powerful lens and forms cohesive social entities amenable to ethnographic exploration. The use of the Internet provides vast fabrics of social textures of people's lives as a valid form of naturalistic inquiry. ${ }^{16,17}$ Using the Internet ethnography through a non-participant observation, we immersed through textual review and in-depth analysis of the personal online blogs among MSM living with HIV/AIDS in the Philippines to illuminate the meaning and essence of their lived experience from country-, culture-specific, and emic perspectives.

We performed an initial search to identify the personal online blogs using the keywords such as Living with HIV/ AIDS, Living with HIV/AIDS blogs, Personal HIV/AIDS blogs, $(\mathrm{N}=100)$ primarily from Blogger and WordPress guided by a purposive sampling technique with inclusion and exclusion criteria presented in Figure 1. A total of 100 blogs were retracted, of which, 60 blogs were removed that did not meet the requirements. Forty blogs were reviewed again using a quality appraisal tool. Of which, 16 blogs that ac-

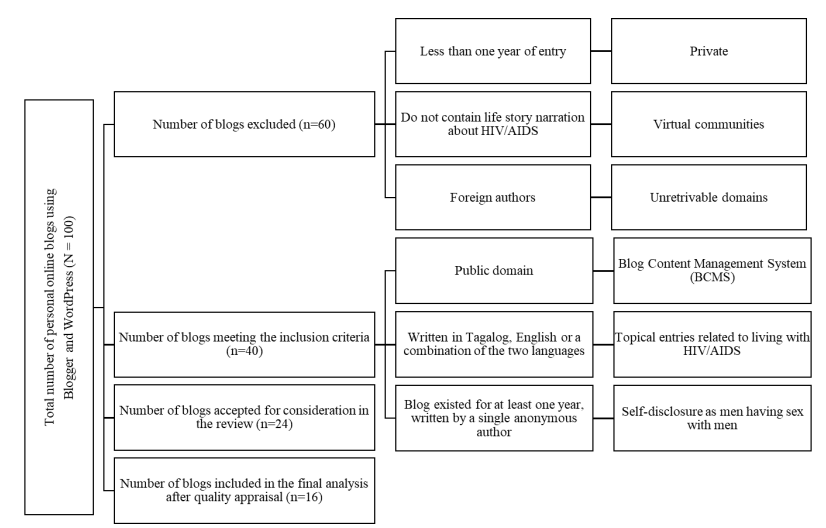

Figure 1

The selection process of personal online blogs for inclusion.

counted for 4,332 entries were saved using NCapture and NVivo for further analysis. ${ }^{18}$

There was no risk associated with the conduct of this study. ${ }^{15,17}$ Personal blogs were in the public domain as a primary source of information were written by anonymous bloggers about their life stories before, during, and after the confirmed diagnosis of HIV/AIDS. We also contacted a self-help organization who do not have direct involvement with the bloggers to reflect on the conceptualized emerging themes based on the life-story narratives.

From the very start of data conceptualization, we bracketed our similar understanding of HIV/AIDS. ${ }^{15,17}$ We also maintained our reflective journals and field notes as critical components for the analysis and interpretation. We allotted three to four months to be familiar with the life-story narration from each blog that represents textual immersion. Data synthesis started from the very first entry to the most recent blog posts that focused on the grand tour question:

"How do personal online blogs authored by MSM living with HIV/AIDS in the Philippines define their life stages before, during, and after the diagnosis?"

Also, this inquiry facilitated the development of various nodes for thematization and other emerging themes found in each blog entry through line-by-line reading to capture the meaning and essence of the narratives. The codes and nodes were grouped to represent reflective interpretation and were shared between and among the research team members as part of the audit trail to reach consensual validation. We also protected the identity of the bloggers through paraphrasing of some verbatim.

\section{RESULTS}

We conducted an Internet ethnography where the world wide web became the data source to illuminate the meaning and essence in the life stages among MSM living with HIV/ AIDS in the Philippines before, during, and after the confirmed diagnosis. Sixteen personal online blogs were included in the final review that accounted for a total of 4,332 entries archived from 2008 to 2019. Majority of the bloggers were newly emerging young professionals between 21-35 years of age, well-spoken in English and Tagalog as evident in their narratives.

The summary of the themes is presented in Figure 2. Through the process of textual immersion and thematic analysis, the life stages among MSM living with HIV/AIDS 
are summarized as follows (a) Stage I Pre-HIV Exposure, (b) Stage II HIV Exposure, (c) Stage III Presumptive Symptomatology, (d) Stage IV Diagnosis, and Confirmatory, and (e) Stage V Post-HIV Diagnosis and Treatment. Accompanying each stage are the emerging psycho-emotive components, task performance, and interplay among the relational agencies' values system. Also, a final reflection was developed that captured the meaning and essence based on the reviewed narratives, as presented in Figure 3.

The HIV life stages among MSM living with HIV/AIDS in the Philippines emulate certain degree of changes about the self that has been considered to be multifaceted dimensions. The person wakes up with full of realization towards life's goals, hopes, and dreams. However, the HIV status of the person contributed to experience the sudden twist from a straight path to an erratic convoluted journey that becomes more complex and perplexing. Ergo, the person immerses to varying psycho-emotive challenges such as denial, anger, bargaining, and depression that take some time to embrace acceptance due to the stigma and discrimination from family, friends, and society at large. Moreover, the HIV life stages heighten what the community can do to address those challenges through acceptance and embodied empathic understanding.

\section{STAGE I PRE-HIV EXPOSURE}

This life stage is where the person develops awareness about the disease, the mode of transmission, and other related concepts associated with it. Sources of information were derived from advertisements, reading materials, radio, or television that heighten their awareness since it became mandatory in the Philippines to enhance the information and dissemination campaigns on HIV testing.

Also, different seminars, symposiums, updates, and workshops are being conducted both in public and private organizations. Some bloggers have also attended seminars to be informed about HIV/AIDS, as reflected in the following narratives:

$$
\begin{aligned}
& \text { "I already have an idea what HIV is because of the fo- } \\
& \text { rums I attended before" (ID-03). } \\
& \text { "Well, I think everybody, to some degree, is aware of } \\
& \text { HIV/AIDS. I was informed then, but that did not stop } \\
& \text { me from having unprotected and risky encounter". } \\
& \text { (ID-12). }
\end{aligned}
$$

Even though most of them were aware of the disease or believed that they would not acquire the disease because of the misconceptions that resulted in their feeling of invincibility.

$$
\begin{aligned}
& \text { "I never thought the day would come when I would } \\
& \text { write about the time I got infected with HIV. I am un- } \\
& \text { able to put the finger on who or when I got affected." } \\
& \text { (ID-01) } \\
& \text { "If you are responsible enough, doing it safely and } \\
& \text { knows how to do it by the unwritten rules, then I think } \\
& \text { it is okay." (ID-04). }
\end{aligned}
$$

This stage coincides with the task performance of life idealization versus life risk-taking. This task performance highlights the person's abilities to develop an understanding of the person's potentials, skills, and capacities in addressing various life's issues and challenges. Life idealization refers to the task performance where a person develops life aspirations associated with the personal goal through the completion of his studies or long-term career.

| "I graduated in the top class in high school; a degree

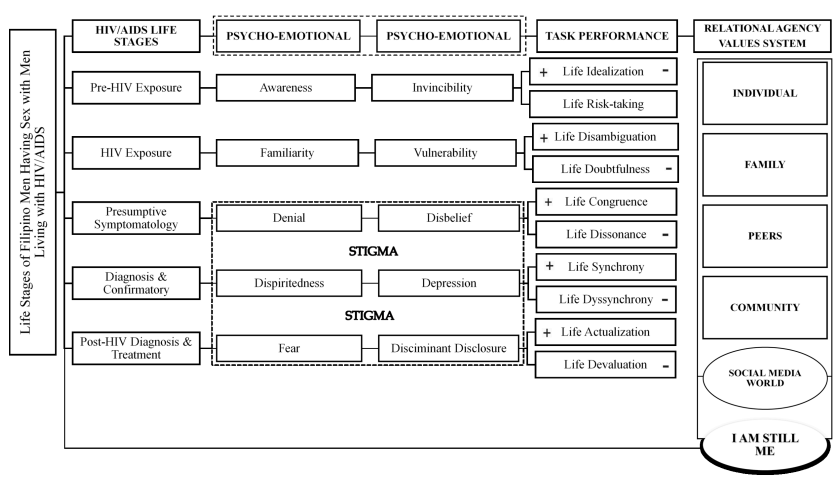

Figure 2

Summary of themes in the meaning and essence in the life stages of MSM living with HIV/AIDS in the Philippines.

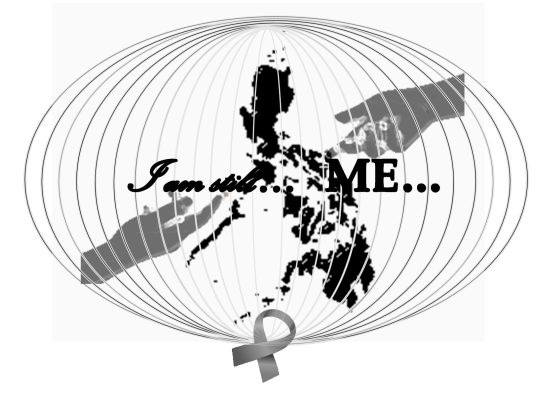

Figure 3

"I am still me" - the overall representation of the meaning and essence in the life stages of MSM living with HIV/AIDS in the Philippines from their life-story narratives.

from a prestigious university, professionally licensed, worked in a world-class healthcare institution; and has more than enough working experience.” (ID-05).

Some bloggers completed their baccalaureate, pursuing postgraduate studies, or currently working. Also, some bloggers have plans to work overseas for higher paying jobs opportunities and help their families in the Philippines.

"My visa arrived. I informed the agency, and they wanted me to finish complying all the requirements. I still did not want to resign. I enjoy being office-in-charge." (ID-05).

Life risk-taking refers to the person's ability to embark on life's journey, congruent to the chosen career. Majority of the bloggers have committed themselves working for their specific goals, either personal or professional growth. This provides an opportunity for them to broaden their potentials, accept the challenges, and adapt to life demands. For the person undiagnosed or diagnosed, he continues to follow the path towards the realization of his life's goals to prove his credence and life course of actions. Also, the person feels independent that helps him to realize his potentials for life survival.

"I remember promising myself that I will not go back to the Philippines if ever I would be given a chance to work abroad. I am independent, and I can survive to live alone by myself. I have exhausted all my resources to pursue this dream." (ID-04). 


\section{STAGE II HIV EXPOSURE}

This life stage is where the person becomes exposed to the disease associated with risky patterns through sexual networking with persons having either low- or high-level infection. Most of the bloggers developed a familiarity about the condition and continue to collect information about the past and present HIV cases reported in the country and publish it in their blog entries. From all the narratives, each blog presented updates about the prevalence and incidence in various regions all over the country. The bloggers also identified multiple treatment hubs for HIV screening, testing, and other support services. This shows the blogger's commitment to providing the most current information because their pages have followers who also want to be informed.

\footnotetext{
“In March 2019 data came out today, and yet again, we have mixed reactions around the rising number of new cases in the country. We look at the numbers, and the most current reports say that we have more than 65,000 cases since 1984." (ID-01).
}

On the contrary, there were few partying, drinking, and taking recreational drugs while having consensual either protected or unprotected encounters. Some spent their times in similar LGBT clubs and even bathhouses. This is where the vulnerability in acquiring the disease comes in although they knew how to be protected, they remained on their usual routines.

\begin{abstract}
"How many people have I had sex with? It was almost twelve years being active before I got infected. I am unable to put the finger on who or when I got affected." (ID-01).

"Something I had wanted to do for some time now. First, just to know for sure that I was negative, and second, only to follow through with my interest in this new March guy and give myself to him wholly and purely" (ID-09).
\end{abstract}

The task performance in this stage is life disambiguation versus life doubtfulness. Life Disambiguation is where the person reflects on one's vulnerability to the disease associated with the risk behaviors. The person dwells into a moment of silence to grasp every detail about the previous experience.

\begin{abstract}
"The downpour of rain cinematically coincided with the fresh wave of torment in my chest. Inside the cab on my way home, the driver might have noticed my strange silence. I take full responsibility in acquiring this disease, I know that. Inside out, however, we look at it, I know that I made a terribly wrong mistake on that fateful January night.” (ID-10).

"I had this because of my own doing, and I can't blame anyone for that. That's the fact of my life I'm wrestling with.” (ID-10).
\end{abstract}

Even most of the bloggers who were familiar with the disease have occasioning doubt associated with myths and facts. This made them question their ability to critically understand and analyze the situations about disease transmission, preventive, and control measures. This also affects how the person accepts being most-at-risk and vulnerable. This refers to the task performance of Life Doubtfulness that accounts for multifaceted concerns, including unemployment or discrimination of people closer to the person.

"However, I was overwhelmed with all the emotions which came crashing down right at that moment. There was that fear of dying. There was that confusion as to what to tell my mother why I cannot go abroad. There was also a fear of unemployment.” (ID-05).

"All this set aside, I was shocked at myself for staying calm. I was more concerned about something else. I was worried about the people who mattered to me.” (ID-14).

\section{STAGE III PRESUMPTIVE SYMPTOMATOLOGY}

This life stage is where the person begins manifesting the presumptive signs and symptoms of the disease including fevers, chills, night sweats, muscle pain, skin rashes, a sore throat, general weakness, swollen lymph nodes or even mouth ulcers. These presumptive signs and symptoms are not fully realized until the person gets tested positive. This has been associated with denial, and the person thinks that those signs and symptoms are typical for simple flu. Since the disease takes time to progress, it will not manifest in the early stage, and this was illuminated by one blogger who was tested with non-reactive results, but in a few months, he sought for hospital admission due to his immunocompromised status.

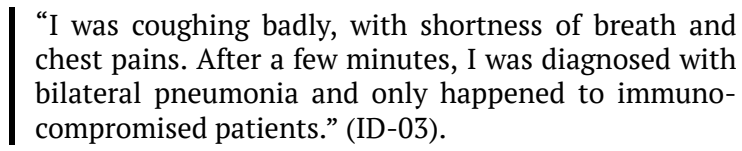

Disbelief is also an interwoven emotion where the person becomes caught between a quandary and realization. It is the time where the person suspects having acquired the disease but do not have the confirmatory results yet.
"My life is healthy until the moment I was seroconvert- ed." (ID-04).
"But I wasn't born with HIV, nor some careless health practitioner transfused me with HIV-infected blood. I had this because of my own doing, and I can't blame anyone for that. That's the fact of my life I'm wrestling with." (ID-10).

The task performance of life congruence versus life dissonance is expected at this stage. Life congruence refers to the task that strengthens the person's values and beliefs consistent on the way he lives his life. Being either diagnosed or undiagnosed with the disease, the person continues to find ways to build harmony between one's core values and desires, thoughts, feelings, and actions. Such interplay becomes an instrument to develop one's resilience when the person approaches the stage of diagnosis and confirmatory.

\footnotetext{
"Do not push your luck, reactive or non-reactive. Know your responsibilities. Appreciate second chances. Life goes on." (ID-01).

"My life is being reconstituted. I am going back to work on the first working day of the year, and I am so excited." (ID-03).
}

On the other hand, Life Dissonance reflects the feelings of discomfort when the presenting information is accurate and correct, but the person tries to counter such perception based on his beliefs. This leads to the overriding of the consonant versus the disconsonant thoughts to avoid withinconflicts or self-tension.

\footnotetext{
"He then asked me again if I was all right. I said, yes. But to be honest, I was overwhelmed with all the emotions which came crashing down right at that moment. There was that fear of dying. There was that confusion as to what to tell my mother why I cannot go abroad." (ID-05).
} 


\section{STAGE IV DIAGNOSIS AND CONFIRMATORY}

This life stage is where the person learns his status from the confirmed results. Most of the bloggers described in their narratives that they were diagnosed during the clinical latency stage after they were admitted to the hospital. For instance, one description mentioned that he was prompted for admission due to shortness of breath while some others were diagnosed with bilateral pneumonia or other accompanying opportunistic infections. During this life stage, the person experiences the feeling of dispiritedness that he could not do anything. One narrated:

"Where do I start? What do I do? How do I get it going? Who would want to expose themselves to this? What do I offer? Who's going to listen to me? Why would anyone want to take part in this?" (ID-09).

Another accompanying emotion is depression commonly experienced by those persons knowing their status for the first time. Due to the abrupt life transition, they had difficulties in understanding what was going on or what went wrong.

"For me, that was the longest afternoon of my life. Everything has taken away from me. Even my tears will not fall anymore. I do not know what to do. I have no one to talk to. I'm starving, but I do not want to eat, and all I want to do is to be in my bed and close my eyes." (ID-04).

"All of these emotions are making my life a roller coaster ride! One moment I am happy, then one moment I am sad, I think this is what they call emotion shift." (ID-13).

Owing to the task performance, the person either will experience life synchrony or life dyssynchrony associated with the diagnosis and confirmatory results. Life synchrony refers to the task where the person accepts his status and continues to believe in multiple possibilities of putting his life back together. The person learns to contemplate, as two bloggers narrated,

"I would come out and tell people about my ordeal. I want to be a resource person, and I want people to look up to me as a fighter. However, for now, I am still at the end of the tunnel, so I need to focus on getting well." (ID-03).

"Now that my 'one-shot' lifetime became more fragile. Maybe this is the time to contemplate and think about if this life is worth sharing for." (ID-04).

On the contrary, life dyssynchrony emerges if the person remains in a quandary and does not know what lies ahead after the confirmed results.

\footnotetext{
"Honestly, at this point, I'm still in the middle of a quarter-life crisis and malleable where to go. However, for now, my purpose is to improve and widen my skill set to help me achieve my long-term goals." (ID-04).

"But there are moments when it takes an effort to be optimistic about things". (ID-13).
}

\section{STAGE V POST-HIV DIAGNOSIS AND TREATMENT}

This is the life stage where the person accepts one' status and the possible changes that he has while receiving the treatment. At this stage, the person complies and undergoes periodic laboratory examination to ensure effective bodily responses to the medication. However, despite the person's acceptance about his status, there was a fear ema- nating from stigma.

"I was newly diagnosed with HIV. I was depressed, uncertain about everything. I got thrown away from my uncle's house and criticized by other relatives." (ID-03). "Fear is that lone wolf waiting to get me, and it finds me too often." (ID-06).

The task performance reflected in this life stage is life actualization and life devaluation. These two opposing tasks are essential to determine the extent of how persons adapt to life changes and transition from having a positive status. Life actualization aims to achieve a sense of accomplishment and fulfilment, both personal and professional. At this stage, the diagnosed person continues to live life to the fullest and has become an instrument of advocacy and community involvement.
"The early diagnosis of HIV has one great blessing that comes with it. Time. Time to reconcile with your ene- mies. Time to heal wounds. Time to touch other peo- ple's lives. Time to look up to the heavens and reconcile with God. Time to create new memories with your loved ones. Time to give back to others." (ID-01).
"I could still do everything like before. I wasn't demot- ed to being just someone sick. I'm still the same me that I was before this chapter of my life." (ID-09).
"Yes, I have HIV, but that should not stop me from mov- ing on and start living a new life." (ID-13).

If the person dwells on fear because of stigma and discrimination, he will submerge towards life devaluation where the feeling of worthlessness and hopelessness emanate. At this task, the person experiences both self and public stigma that results in isolation, feeling of disgrace, and desolation.
“I'm crying a river. I don't know why, maybe all the burdens, frustrations and disappointment since I was a child erupted suddenly." (ID-04).
"I am learning to be more and more tolerant these days, but it is hard sometimes when you want to switch off about your condition and be like others. I must be on the lookout continually, so I do not expose my HIV to people." (ID-06).

\section{EMBEDDED AND EMBODIED STIGMA IN THE LIFE STAGES AMONG MSM LIVING WITH HIV/AIDS}

Stigma has been in co-existence in the lives of MSM living with HIV/AIDS. An embedded stigma is something that has been insinuated to the person's status as if he is abnormal, while embodied stigma refers to the self-inflicting feeling of worthlessness. Stigma remains a multifaceted dimension unexplored alongside its effects based on the bloggers' narratives.

"The fact is, all my fears did happen. The first person who stigmatized and discriminated me were my parents, along with some of my relatives. It was like every day that I wake up everything just keeps getting worse." (ID-02).

"She said [the doctor] part of her contract with the school is that she must disclose all the employee's health status, especially if condition considered critical. That she couldn't just confirm my fit to work without explaining the hazard of my situation. Because of my health, I may not be able to perform some job responsibilities of the position.” (ID-08).

"I know she [the doctor] felt some pity for me. I was young. I had gotten tested on a whim, and not because I was feeling something terrible. I was turning 30 tomor- 
row. I was alone.” (ID-09).

"She said that it was not discrimination on their part, and their decision has nothing to do with my HIV status. It is just that they are afraid that while I am doing the duties and responsibilities of the job, something terrible and health-related might happen to me due to the long working hours and the workload.” (ID-16).

\section{RELATIONAL AGENCIES’ VALUES SYSTEM}

The life stages depicted in this study revealed overarching psycho-emotive components and task performance that could be affected by the values system inherent to the individual, family, peers, community, and the social media world that play an essential role towards acceptance of the disease and eventually life transition and the changes associated with it.

For instance, at the person's level, if he lacks understanding about the disease, and misguided between myths and facts, he remains at risk and dwells on depression and isolation. However, if the person has a robust coping mechanism and related skills, he would consider the illness as a challenge and an opportunity.

"I take full responsibility in acquiring this disease, I know that. Inside out, however, we look at it, I know that I made a mistake on that fateful January night. I'm not passing the blame on someone and not faulting anyone but my own. But somehow, it's hard when it's rubbed on my face." (ID-10).

On the other hand, the individual values system is also dependent on other relational agencies. For instance, the family involvement coincides with the disclosure about the person's status as narrated:
"I could not imagine a life without him [father] by my side. He did not ask me why it happened. He showed me that everything will be fine." (ID-02).
"I told my parents about my health condition. It was a relief. Although there is guilty feeling that they have to know the bigger picture. But they are old to worry and completely understand my condition. With my sis- ter and friends behind me, I know I'll get through." (ID-07).
"Nanay [mother] gave me strength and courage. She is more than what antiretroviral drugs can provide. She is my medicine. When it comes to love, Nanay is the word." (ID-08).
"I admitted first being gay as what I really am. From then on, I said I have AIDS (as it was the most un- derstandable term about being HIV positive. Everyone cried including my mother, father, and sister.” (ID-11).

On the contrary, not all would dare disclose to their families where fear remains a common reason as narrated:

"The first person who stigmatized and discriminated me were my own parents, along with some of my relatives. It was like every day that I wake up everything just keeps getting worse." (ID-02).

"The fact that I came out to be positive was easy for me to take in. But what's hard for me is when I see people who are special to me, unable to accept the whole fact about me." (ID-14).

"She [mom] had a hard time accepting me, until now she's not $100 \%$ comfortable with it, we don't talk about it either. She doesn't want me to explain everything to her. She doesn't want me to tell my dad. She doesn't want me to come out of the world because people might be scared. People might not come close or near me, and that's how my mom took it. What if it was someone else
| who doesn’t even know me?" (ID-15).

Also, having a partner contributes to a more effective preparation about the disease, compliance with the therapeutic regimen, and other HIV-related required services.

"I’m so lucky. I have a reliable support system. It makes me feel positive all the time. It makes me feel confident about my treatment. I have a loving partner." (ID-03). "HIV made me a better lover. He accepted my status and stayed with me. This is by far the greatest love I ever felt." (ID-08).

Furthermore, peers facilitate acceptance. For instance, those self-help groups or organisations that cater to HIV related services can be a constant companion to enhance the awareness and understanding about the disease, other related services, and even disclosure.
"HIV Anonymous would help our newly diagnosed PL- HIV psychologically, emotionally, spiritually, and phys- ically." (ID-02).
"I'm happy that there is a community who helps HIV+ like me." (ID-11).
"My best friend knows about my status, and she is pos- itive about it, I did not see her cry not even one drop of tear, she just told me that we would conquer the world together." (ID-15).

The social media world as a community opens the doors to MSM re-building their connections, to enhance their understanding of the disease, and disclosing one's status even without knowing his identity.
"So why am I writing? Simple. To reach out to people who are still afraid like me. Who are still scared about treatment, of the stigma, of facing families and friends, of being weak and emotionally unprepared for the big battle, of what the future entails us?" (ID-03).
"This is my tool and my way to reach out to other people, especially those who have the same condition as mine. Today we stand united, not just in spreading awareness about HIV/AIDS. We stand united in fighting the stigma." (ID-07).
"I hope it is just all right, maybe to touch other people's lives in this way. I want to write my own thoughts." (ID-16).

\section{“I AM STILL ME": MEANING AND ESSENCE IN THE LIFE STAGES AMONG MSM LIVING WITH HIV/AIDS IN THE PHILIPPINES}

Figure 3 presents the overall interpretation of the meaning and essence in the life stages among MSM in the Philippines. HIV life stages were described as a process of transitioning from awareness to disbelief that they have the disease to accepting and moving forward beyond the disease. The life stages among MSM, as perceived in the personal online blogs, have been an abrupt and disjointed transition most of the population represented in this ethnographic exploration are all newly emerging professionals who have the life aspirations for themselves, families, and communities where they belong. Like any other healthy persons, primarily those undiagnosed remain in a continuum of life struggles, so much so, among those persons diagnosed with HIV experiencing and overshadowing burden of stigma that contributed to the amalgamated psycho-emotive effects such as denial-disbelief, dispiritedness-depression, and fear-discriminant disclosure. Stigma whatever forms it takes, it leads to the feeling of worthlessness and hopelessness. 
"I want to be an advocate on the HIV/AIDS issue and a peer educator. I want people to learn a lesson from what happened to me. But the more I think about it, the more I become hesitant to carry it out because of the risks involved, not to mention the stigma and discrimination that my loved ones and I will face.” (ID-13).

The concept of "I am still me" is an all-encompassing representation to better understand the situations of PLWHA in the Philippines. This concept was derived from perceptions of MSM across HIV life stages and underscored how they struggle, cope and adapt into new ways beyond their disease. The country is encapsulated in the web of socio-cultural, economic, and political spirality regarding HIV/AIDS commonly identified as critical factors affecting the lives of MSM. This represents the multidimensional spheres that prevent the person from accepting his status, disclosure, and positive outlook towards effective life transition after receiving the confirmed results of HIV. The two hands represent the amalgamated efforts of individuals, families, community, and the government in reaching out the most-at-risk and vulnerable population through various forms of campaigns, free testing and screening, and other HIV-related services. The ribbon symbolizes the life-enabling potentials of PLWHA to be part of a broader community, and their involvement is an essential factor to heighten further awareness of those persons who harbor fears to get tested and informed.

"I am still me" further shows the commonality among the MSM living with HIV/AIDS from their life-story narration and views each person as a whole and complete having a sense of humanity. However, the MSM and other PLWHA continue to suffer from stereotypes, prejudice, and discrimination inherent to stigma formation. For this reason, the community should be humane to embrace them to fully experience the love, belongingness, and self-esteem contributing to life actualization. As the cases of HIV among MSM is on the rise due to some factors emanating within the culture-specific domain, zero tolerance to discrimination should be advocated. This can be done through openness to multiple possibilities in enhancing each person's potentials to be part, involved, and empowered in joint and collaborative partnerships in understanding the life struggles among MSM living with HIV/AIDS.

\section{DISCUSSION}

HIV/AIDS is still one of the global health threats. Both developed and developing countries strive much to address the increasing HIV related cases primarily on the most-atrisk and vulnerable population through campaigns funded by the government and international organizations. Although those campaigns are massive, such strategies have not been entirely successful because of the culture-specific stigma existing in the Philippines. For this reason, the stigma needs to be viewed from its various forms to learn its long-term effects and develop a critical awareness of PLWHA and how they lived their lives.

Moreover, a person cannot withstand the burden because of the stigma from the preconceived notions about HIV/ AIDS that leads to a self-inflicting belief that the disease should be kept confidential. As a result, the more obtrusive feeling of self-damage, self-doubt, and self-devaluation become imminent. It is then imperative to immerse into the life stages among Filipino MSM living with HIV/AIDS for us to develop empathic accuracy, caring thinking, and emotional synchrony. These are the essential requisites for compassionate and humane service for far-reached, mostat-risk, vulnerable, and diagnosed populations.

Using Internet ethnography is one of the critical steps that the researchers have undertaken. Although there were no actual contacts or interviews performed, the text-based life scenarios widened our perspectives to realize the multifaceted reasons why most of the bloggers immersed in the blogosphere. They want to be informed and to inform the public, share their feelings, thoughts, and desires, and most importantly to reinvigorate themselves on the abrupt changes that took place in their lives after being diagnosed with HIV/AIDS.

The life stages analysis also amplified our knowledge about the psychological implication surrounding the disease but not often considered by other ethnographers or researchers alike because it is time-consuming reading and re-reading through texts. However, we realized as internet ethnographers, our indulgence to life-story narration is only a prelude linking with some of the theoretical models including Sullivan (1953) who viewed person having a capacity to establish intimacy as a source of life satisfaction. ${ }^{19}$ Erickson (1963) explicated that developing a self-identify helps an individual to face the loss of ego that leads to isolation and self-absorption. ${ }^{20}$ Rogers (1970) concluded that loneliness requires others to approach the person in a caring manner that influences the development of a well-functioning person. ${ }^{21}$ Also, Maslow (1943) mentioned that human needs depend on the hierarchy. ${ }^{22}$ Beyond this theoretical linking is the self-realization-to care in communion with others specifically the PLWHA which further means to embody the acts of love, faith, hope, and charity. ${ }^{23}$ By looking at the life struggles, we found a shared vulnerability and empathic accuracy that moved us beyond the textual immersion-genuine and sustained commitment to advocacy.

Also, the life stages through life-story narration from online blogs should be viewed as an instrument for healthcare providers to immerse and realize the current demeaning situations of MSM in the Philippines. This calls for the healthcare communities to remain at the frontlines of health promotion and education, information and dissemination, and translation of knowledge to cascade care for all the PLWHA. The HIV/AIDS continues to be a global concern, and the Philippines is fast approaching the first rank among other countries. For this reason, there is a call to sustain the involvement with the PLWHA, families, communities, and society at large identified as relational agencies with an embodied values system to address the multifaceted needs of PLWHA, to cascade HIV care and to heighten information dissemination.

"I am still me" is a symbolic representation that summarises the meaning and essence in the life stages among MSM living with HIV/AIDS. This personifies that person has not lost its humanity because of the disease but should be viewed as whole and complete. Although their life struggles are immeasurable, they never stop believing that there is a life beyond the disease. Such a realization made themselves to become more agile and resilient from the challenges that they are facing. "I am still me" personifies the values system that we need as a community to develop the embodied compassion, emphatic understanding, shared vulnerability, and humanistic approach to HIV/AIDS care owing to the psychological and mental health among MSM living with HIV/ AIDS.

\section{CONCLUSION}

The Internet ethnography although remains a relatively 
new approach, it provided the researchers' robust information from the world wide web to achieve the primary purpose of this study - to illuminate the meaning and essence in the life stages among MSM living with HIV in the Philippines. The use of this approach offers no geographic boundaries, allows researchers to study those who may decline from participating in the traditional qualitative study due to stigma, no recall bias, and an ultimate naturalistic inquiry while exploring topics that are of importance to the participant. However, there are limitations in the use of this approach, such as having difficulty in having narrow inclusion and exclusion criteria, and unable to confirm identity or validate the diagnosis, treatment modalities, symptombased experiences.

Moreover, the findings of this study contributed to the unexplored area of HIV-related research that focuses on the lives of MSM in a country-, culture-specific, and emic context. From then, it hopes to provide a humanistic view towards MSM and other PLWHA to realize their worth and sense of humanity. Although they have been afflicted with the disease, it did not change them as a person but rather enhances their potentials, became adaptive, resilient, and renewed. From the life stages analysis, it brings us closer to real-life situations and reflective practice towards the care of HIV/AIDS.

Indeed, the meaning and essence of living with HIV/ AIDS is not an ordinary journey for the people who lived shorter, longer, and currently living with the disease. It is a lifetime commitment, involvement, and empowerment among the individuals, families, communities, and social media world. The fight against the condition does not offer a one-size-fits-all strategy but should be holistic, comprehensive, integrative, humanistic, and compassionate. From then, we could say-we are arriving at 'the end of stigma.' "We are $O N E$ " and "We are in communion in caring with $P L W H A "$ must be revitalized in every national and global agenda.

\section{ACKNOWLEDGEMENTS}

Funding information: No funding was obtained for this study.

Competing interests: The authors have completed the Unified Competing Interest form at http://www.icmje.org/ coi disclosure.pdf (available on request from the corresponding author) and declare no conflicts of interest.

Disclaimers: This publication reflects only the authors' views, and the European Union is not liable for any use that may be made of the information contained herein.

Correspondence to:

Cyruz P. Tuppal, PhD, PhDNS, MSN, MASPED, MBA, MHA, PGD, RM, RN, LPT

School of Health Sciences

St. Dominic College of Asia

Brgy. Talaba

Bacoor Cavite

Philippines

cyruz_tuppal@sdca.edu.ph 


\section{REFERENCES}

1. Farr AC, Wilson DP. An HIV epidemic is ready to emerge in the Philippines. J Int AIDS Soc. 2010;13(1):16. doi:10.1186/1758-2652-13-16

2. Parry J. Philippines faces expanding HIV epidemic, shows research. BMJ. 2010;340:c2589-c2589. doi:10.1 136/bmj.c2589

3. Gangcuangco LMA, Tan ML, Berba RP. Prevalence and risk factors for HIV infection among men having sex with men in Metro Manila, Philippines. Southeast Asian J Trop Med Public Health. 2013;44:810-817.

4. Ross AG, Ditangco RA, Belimac JG, et al. HIV epidemic in men who have sex with men in philippines. Lancet Infect Dis. 2013;13(6):472-473. do i:10.1016/s1473-3099(13)70129-4

5. Senate Economic Planning Office. Addressing a national health threat: The Philippine HIV epidemic. 2018.

6. UNAIDS. UNAIDS’ Terminology Guidelines. 2007. $\underline{\mathrm{h}}$ ttps://www.iasociety.org/Web/WebContent/File/unaid s terminology_guide_en.pdf. Accessed August 24, 2019.

7. Maman S, Abler L, Parker L, et al. A comparison of HIV stigma and discrimination in five international sites: The influence of care and treatment resources in high prevalence settings. Soc Sci Med. 2009;68(12):2271-2278. doi:10.1016/i.socscimed.200 $\underline{9.04 .002}$

8. Chollier M, Tomkinson C, Philibert P. STIs/HIV Stigma and health: A short review. Sexologies. 2016;25(4):e71-e75. doi:10.1016/j.sexol.2016.03.005

9. Ainlay SC, Lerita CM, Becker G. Stigma reconsidered. In: Ainlay SC, Lerita CM, Becker G, eds. The Dilemma of Difference A Multidisciplinary View of Stigma. New York: Plenum Press; 1986.

10. Parameswari S, Jayapoorani N. Effects of HIV related stigma on the lives of persons living with HIV. BMC Infect Dis. 2012;12(Suppl 1). doi:10.1186/1471-2 334-12-s1-p52

11. Herek GM, Capitanio JP, Widaman KF. Stigma, social risk, and health policy: Public attitudes toward HIV surveillance policies and the social construction of illness. Health Psychol. 2003;22(5):533-540. doi:1 $\underline{0.1037 / 0278-6133.22 .5 .533}$
12. Kamaradova D, Latalova K, Prasko J, et al. Connection between self-stigma, adherence to treatment, and discontinuation of medication. PPA. 2016;Volume 10:1289-1298. doi:10.2147/ppa.s99136

13. Xu X, Sheng Y, Khoshnood K, Clark K. Factors Predicting Internalized Stigma Among Men Who Have Sex with Men Living with HIV in Beijing, China. J Assoc Nurses AIDS Care. 2017;28(1):142-153. doi:1 0.1016/j.jana.2016.08.004

14. Hasan MT, Nath SR, Khan NS, Akram O, Gomes TM, Rashid SF. Internalized HIV/AIDS-related stigma in a sample of HIV-positive people in Bangladesh. $J$ Health Popul Nutr. 2012;30(1):22-30. doi:10.3329/jhp n.v30i1.11272

15. Eastham LA. Living with HIV: Views through the Blog. 2011.

16. Hine C. Ethnography for the Internet: Embedded, Embodied and Everyday. London: Bloomsbury Publishing; 2015.

17. Keim-Malpass J, Steeves RH, Kennedy C. Internet ethnography: A review of methodological considerations for studying online illness blogs. Int $J$ Nurs Stud. 2014;51(12):1686-1692. doi:10.1016/i.ijnu rstu.2014.06.003

18. International QSR. NVivo Qualitative Data Analysis Software. 11.4.0. QSR International Pty Ltd; 2016.

19. Sullivan HS. The Interpersonal Theory of Psychiatry. New York: W. W. Norton Company; 1953.

20. Erikson EH. Identity: Youth and Crisis. New York: W. W. Norton Company; 1968.

21. Rogers CR. Encounter Groups. New York: Harper \& Row; 1970.

22. Maslow AH. A theory of human motivation. Psychol Rev. 1943;50(4):370-396. doi:10.1037/h00543 $\underline{46}$

23. Tuppal CP. Towards a Theory of Communion in Caring. In-press. 2019. 